\title{
Variability in the Population of Alternaria brassicicola Causing Dark Spot of Mustard
}

\author{
Abhishek Kumar ${ }^{1 *}$, Chanda Kushwaha ${ }^{1}$, Chandan Kishore ${ }^{2}$, \\ Subhashish Sarkhel ${ }^{1}$ and Ravi Shankar Singh ${ }^{2}$
}

\author{
${ }^{1}$ Department of Plant Pathology, Bihar Agricultural University, Sabour, \\ Bhagalpur-813210, India \\ ${ }^{2}$ Department of Plant Breeding and Genetics, Bihar Agricultural University, Sabour, \\ Bhagalpur-813210, India
}

*Corresponding author

Keywords

Alternaria

brassicicola,

Mustard,

variability

Article Info

Accepted:

08January 2020

Available Online:

10 February 2020

\section{A B S T R A C T}

Mustard is one of the important oilseed crop in the country. It contributes $26.5 \%$ to the total domestic edible oil production. Alternaria blight is one of the major factor in the reduction of yield and quality which ranges from $15-71 \%$ depending upon the severity of the disease. The present study was undertaken to evaluate diversity among different isolates of Alternaria brassicicola collected from various regions of Bihar and adjoining parts. A total of sixteen isolates were collected from Saharsa, Supaul, Darbhanga, Khagaria, Samastipur, Bhagalpur, Gaya, Munger and Varanasi and its cultural, morphological, pathological, biochemical and genetic variability were studied. Isolates showed variability with respect to colony characters from olive gray to dark brown, radial growth rate ranged from $4.6 \mathrm{~mm} /$ day to $11 \mathrm{~mm} /$ day, and sporulation capacity showed variation from $33 \times 10^{4}$ spores $/ \mathrm{ml}$ to $134 \times 10^{4}$ spores $/ \mathrm{ml}$. Substantial variation was found in spore morphology with respect to conidial length, width and number of septa. Incubation period of isolates varied from 48 hours to 96 hours. There was significant positive correlation between growth rate and sporulation $(\mathrm{r}=0.74)$.

\section{Introduction}

India is one of the leading mustard growing areas of the world with respect to production, consumption and import in vegetable oils.
Rapeseed-mustard has significant role to play to meet the growing demand of edible oils from domestic production. The productivity of this crop is greatly affected by much biotic and abiotic stress. Among biotic stresses 
occurrence of Alternaria blight is most significant and is referred to as chronic disease of mustard (Meena et al., 2010). Alternaria blight is caused by Alternaria brassicae and Alternaria brassicicola. Reports indicates prevalence of $A$. brassicae at relatively low temperatures whereas $A$. brassicicola at higher temperature regimes (Humpherson-Jones, 1989). It is also suggested that globally there is a rise in temperature and duration of low temperature regimes is shortened (Hansen et al., 2010). Under such situation occurrence of $A$. brassicicola on mustard will likely gain more importance. Kolte, (1985) reported that the disease causes an average yield loss of 46.0 $47.0 \%$ in yellow sarson and 35.0-38.0 \% in Indian mustard in India. Kumar and Kolte, (2001) observed that Alternaria blight is one of the important diseases of Brassica responsible for average yield loss of 10.0 to 70.0 per cent at different parts of the Northern India depending upon the severity. Mondal, (2008) reported yield losses up to 10.0 to 40.0 per cent every year by Alternaria blight in old alluvial zone of northern part of West Bengal. For understanding of epidemiology, hostpathogen co-evolution, and resistance management, knowledge of plant pathogen variation is required. The present study was undertaken to evaluate diversity among different isolates of Alternaria brassicicola collected from various regions of Bihar and adjoining parts (Table 1.)

\section{Materials and Methods}

The cultural characteristics were recorded on $10^{\text {th }}$ to $15^{\text {th }}$ days after inoculation of all the isolates of $A$. brassicicola. Petri plates containing potato dextrose agar (PDA) were inoculated with a $3 \mathrm{~mm}$ diameter cork bore obtained from the margin of 5 to 7 days old culture grown in the PDA. Characters like colony growth was recorded from $10^{\text {th }}$ to $15^{\text {th }}$ days after inoculation while colony colour, appearance, shape, margin and zonation were recorded after $12^{\text {th }}$ days by direct observation of culture grown in Petri plate on PDA which was incubated in BOD incubator at $27 \pm 2{ }^{\circ} \mathrm{C}$ temperature. Further the isolates of $A$. brassicicola were categorised into three groups on the basis of growth rate i.e. fast growing, moderate growing and slow growing. The observations on colony colour were recorded seven days after inoculation. The colour of the colony was observed from the top and bottom side of the culture plates. Based on the colony colour, the cultures were assigned to different groups.Observations for the colony texture was recorded on seventh day after inoculation when the growth covered full Petri plate. The isolates were designated to different groups based on nature of the texture of their mycelial growth and appearance. The average growth was recorded in terms of diameter of Petri plate. For radial growth measurement, $20 \mathrm{ml}$ of sterilized medium was poured in sterilized Petri plates. After solidification, the Petri plates were inoculated with seven-day old culture block of $2 \mathrm{~mm}$ diameter placed inverted in the centre of the plate and incubated at $25 \pm 2{ }^{\circ} \mathrm{C}$ in BOD incubator. Radial growth pattern of the A. brassicicola colonies were observed. The average growth was recorded in terms of diameter of Petri plate. Based on radial growth, the cultures were assigned to different groups. Spore count per $\mathrm{ml}$ was estimated with the help of haemocytometer from the spore suspension made from different isolates. Twelve days old culture was used for the study. A bit of $2 \mathrm{~mm}$ size was cut with the help of cork borer from half the distance of centre and periphery. Triton 20 was used as surfactant in the suspension. The number of spores per ml was calculated with the help of standard formula derived for the haemocytometer as:

Number of spores per $\mathrm{ml}=$ number of spore counted per square (average of four square on the corner and one central square) $\times 10^{4}$. 
The pathogenicity test was conducted by detached leaf technique in-vitro in moist chamber. The leaves of Brassica juncea cultivar Varuna were kept in sealed Petri plates both surface covered by filter paper which was moistened by distilled water. The setup was placed in growth chamber at $25 \pm 2$ ${ }^{\circ} \mathrm{C}$ and at $75 \%$ relative humidity and incubation period was noted for all isolates. The observations were recorded at different time viz; 24 hours 48 hours, 72 hours and 96 hours after inoculation.

For studying morphological variability among the isolates of the Alternaria brassicicola ocular microscope was calibrated and by use of micrometre scale (Meena et al., 2005), conidial variability among 16 isolates of $A$. brassicicola was observed. Temporary slide was prepared from 12 days old culture stained with cotton blue lectophenol. Total of 100 conidia from each isolate was examined at $40 \times$ magnification of light microscope and measure using ocular and stage micrometre. The important characteristics like conidial length, breadth, number of horizontal and vertical septa were observed under the light microscope. The average was used to calculate the conidial length, breadth, number of horizontal and vertical septa.

\section{Results and Discussion}

\section{Cultural variability}

In the present investigation cultural, morphological and molecular diversity in various isolates of A.brassicicola infecting rapeseed-mustard was observed. The results showed that isolates of A. brassicicola differ in their colony characters, growth rate and sporulation.

Most of the isolates of A. brassicicola showed different colony color on PDA (Table2). The color varied from whitish to black. Similar observations were also noticed were different pigmentation on isolates of Alternaria spp. was observed (Ramegowda, 2008). Other colony characters such as texture, culture margin and appearance of mycelial growth were highly varied among the isolates (Figure 2). Variation was observed in color of the colony as well as growth rate (Table 2, Table $3)$. Based on the growth rate isolates were categorized as fast growing as well as slow growing. Such variation in growth rate in a pathogen was also reported by Deep et al., 2014.

\section{Sporulation and growth rate}

Spore production or sporulation capacity plays a major role in disease epidemics by affecting the pathogen's ability to spread the disease and cause successful infection (Agrios, 2008). Sporulation capacity of isolates of A. brassicicola varied from 33 $\times 10^{4}$ spores $/ \mathrm{ml}$. to $134 \times 10^{4}$ spores $/ \mathrm{ml}$. Most of the isolates had medium sporulating capacity ranging from $57 \times 10^{4}$ spores $/ \mathrm{ml}$ to $105 \times 10^{4}$ spores $/ \mathrm{ml}$. (Table 4) There was high positive correlation $(\mathrm{r}=0.74)$ of sporulation capacity with growth rate indicating that most of the fast growing isolates were producing more spore when compared to slow growing isolates.

\section{Pathogenic variability among the isolates of} Alternaria brassicicola

The pathogenicity of different isolates of $A$. brassicicola were carried on the susceptible cultivar Varuna. The leaves at the third node were used for the study. After inoculation leaves were kept in the moist chamber. Isolates showed differences in the incubation period from 48 hours to 96 hours. The symptoms appeared as light brown spot on leaves and was surrounded by yellow halo (Figure 4) 


\section{Morphological variation}

Length and breadth of spore as well as horizontal and vertical septa was observed for each of the isolate of A. brassicicola. Data collected when analyzed statistically showed significant variation in the length and breadth of the spore as well as horizontal and vertical septa indicating that morphologically distinct population of $A$. brassicicola exists in the region. Most of the isolates (11) showed length of spore within the range of 21.71$29.17 \mu \mathrm{m}$ (Table 5) which is in conformity with the previous reports (Meena et al., 2010, Kumar et al., 2014). Very few isolates namely 3 showed shorter length $(14.25-21.71 \mu \mathrm{m})$ and 2 isolates showed relatively longer length of the spore (29.17-36.63) respectively. The finding indicates towards relative dominance of the isolates with length of spore between 21.71-29.17 $\mu \mathrm{m}$ that constitutes $68 \%$ of the total isolates under study.

Table.1 Locations and parts of the plant from where isolates were collected

\begin{tabular}{|c|c|c|c|}
\hline Sl. No. & Isolate & Location & Part of plant used \\
\hline 1. & I 1 & Rajandipur, Bhagalpur & Leaves \\
\hline 2. & I 2 & Naugachia, Bhagalpur & Leaves \\
\hline 3. & I 5 & Sabour, Bhagalpur & Leaves and pod \\
\hline 4. & I 7 & Jamalpur, Munger & Leaves \\
\hline 5. & I 8 & $\begin{array}{l}\text { College farm, Bihar agriculture } \\
\text { university, Bhagalpur }\end{array}$ & $\begin{array}{l}\text { Leaves, stem and } \\
\text { seeds }\end{array}$ \\
\hline 6. & I 9 & Bariyarpur, Munger & Leaves \\
\hline 7. & I 11 & $\begin{array}{l}\text { Rajendra central agri. } \\
\text { University farm, Samastipur }\end{array}$ & Leaves \\
\hline 8. & I 12 & Mansi, Khagaria & Leaves \\
\hline 9. & I 13 & Birpur, Supaul & Leaves \\
\hline 10. & I 14 & Bodhgaya, Gaya & Leaves \\
\hline 11. & I 15 & Darbhanga & Leaves \\
\hline 12. & I 16 & Nauhatta, Saharsa & Leaves and pods \\
\hline 13. & I 17 & Shivpur, Banaras & Leaves \\
\hline 14. & I 18 & Chittaipur, Banaras & Leaves \\
\hline 15. & I 19 & Sultanganj, Bhagalpur & Leaves \\
\hline 16. & I 23 & Khankitta, Bhagalpur & Leaves \\
\hline
\end{tabular}


Table.2 Colony color and texture of isolates of A. brassicicola

\begin{tabular}{|c|c|c|c|c|c|}
\hline \multirow[t]{2}{*}{ SI. No. } & \multirow[t]{2}{*}{ Isolate } & \multirow[t]{2}{*}{ Colony color } & \multicolumn{3}{|c|}{ Cultural characteristics } \\
\hline & & & $\begin{array}{l}\text { Circular/ } \\
\text { irregular }\end{array}$ & $\begin{array}{c}\text { Smooth/ } \\
\text { rough }\end{array}$ & Zonation \\
\hline 1. & I 1 & Olivaceous grey & Circular & Smooth & Yes \\
\hline 2. & I 2 & Brown & Circular & Smooth & Yes \\
\hline 3. & I 5 & Greyish brown & Irregular & Smooth & No \\
\hline 4. & I 7 & Light olive green & Circular & Smooth & Yes \\
\hline 5. & I 8 & Brown & Circular & Smooth & Yes \\
\hline 6. & I 9 & Chocolate brown & Irregular & Rough & No \\
\hline 7. & I 11 & Greyish brown & Circular & Rough & Yes \\
\hline 8. & I 12 & Greenish straw & Circular & Rough & Yes \\
\hline 9. & I 13 & Light olivaceous green & Circular & Smooth & Yes \\
\hline 10. & I 14 & Dark brown & Circular & Smooth & Yes \\
\hline 11. & I 15 & Grey & Circular & Smooth & Yes \\
\hline 12. & I 16 & Whitish grey & Circular & Smooth & Yes \\
\hline 13. & I 17 & Light brown & Circular & Smooth & Yes \\
\hline 14. & I 18 & Dark brown & Circular & Smooth & Yes \\
\hline 15. & I 19 & Light greyish brown & Irregular & Rough & No \\
\hline 16. & I 23 & Olivaceous green & Circular & Smooth & Yes \\
\hline
\end{tabular}

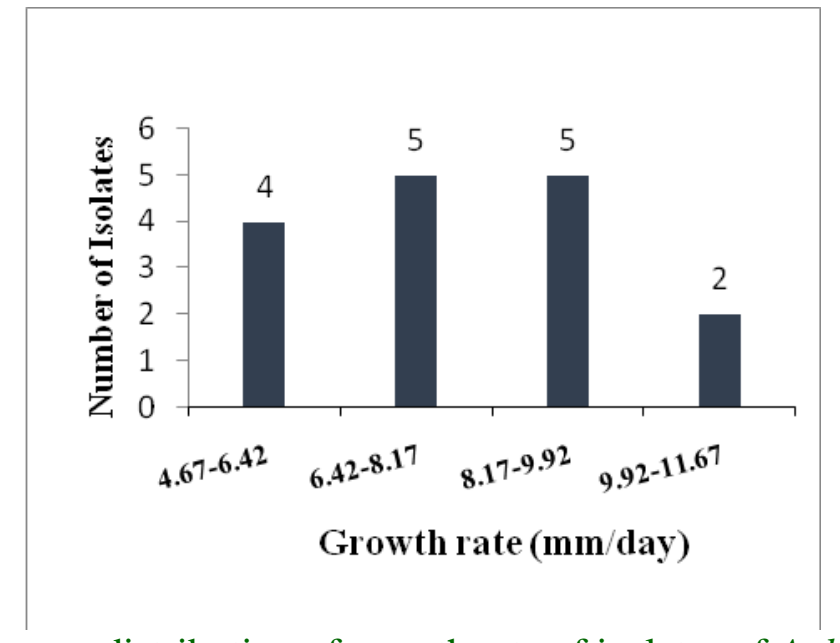

Fig.1 Frequency distribution of growth rate of isolates of A. brassicicola 

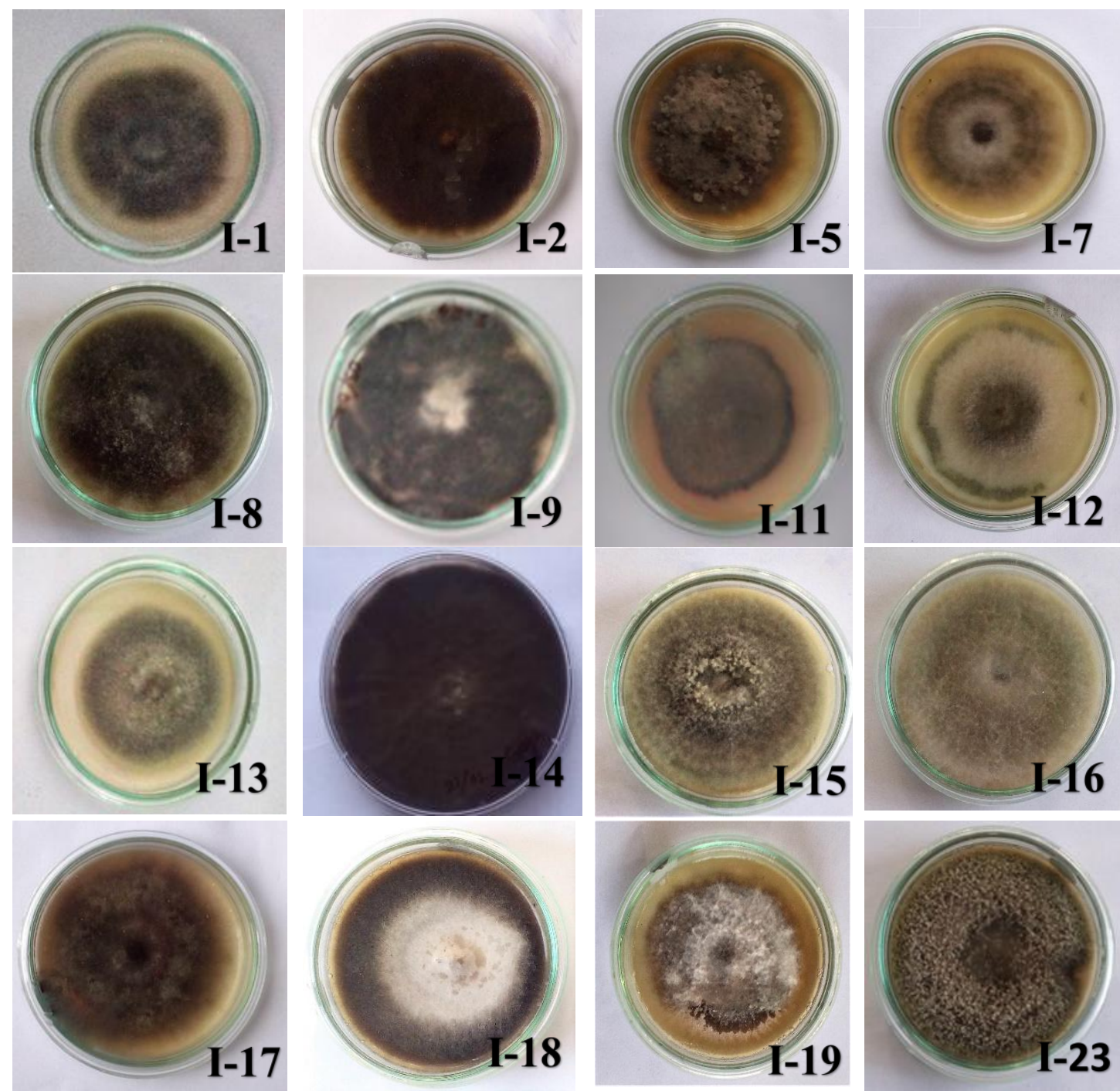

Fig.2 Colony color and texture of different isolates of A. brassicicola

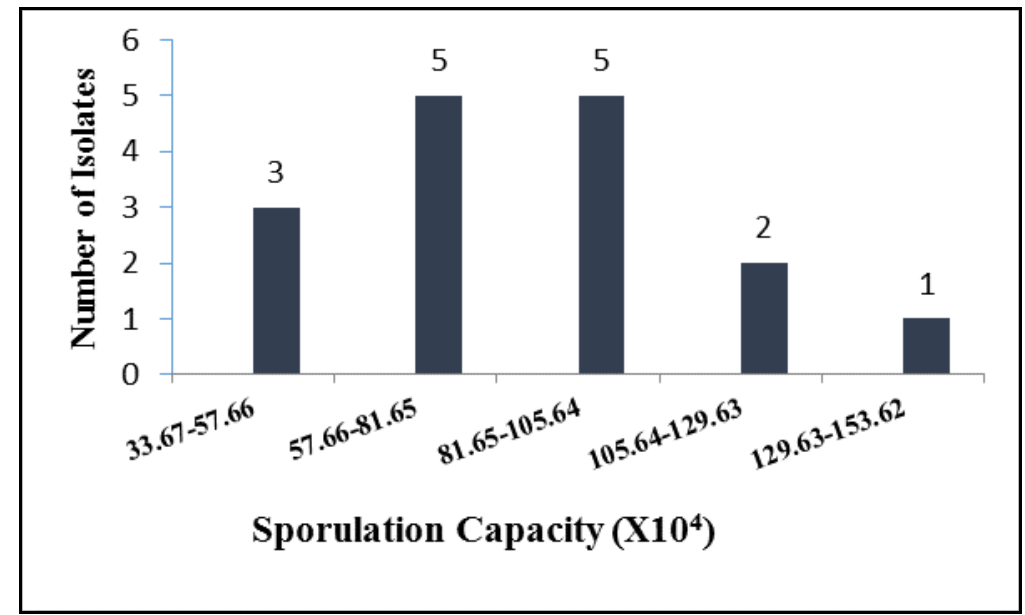

Fig.3 Frequency distribution of sporulation capacity of isolates of A. brassicicola 
Table.3 Growth rate of fungal colonies of isolates of A. brassicicola

\begin{tabular}{|l|c|c|}
\hline SI. No. & Isolates & $\begin{array}{c}\text { Growth rate on } \\
\text { PDA }\end{array}$ \\
\hline $\mathbf{1 .}$ & I 1 & 6.67 \\
\hline $\mathbf{2 .}$ & I 2 & 4.67 \\
\hline $\mathbf{3 .}$ & I 5 & 8.50 \\
\hline $\mathbf{4 .}$ & I 7 & 8.67 \\
\hline $\mathbf{5 .}$ & I 8 & 8.50 \\
\hline $\mathbf{6 .}$ & I 9 & 6.33 \\
\hline $\mathbf{7 .}$ & I 11 & 6.33 \\
\hline $\mathbf{8 .}$ & I 12 & 11.00 \\
\hline $\mathbf{9 .}$ & I 13 & 9.33 \\
\hline $\mathbf{1 0 .}$ & I 14 & 7.33 \\
\hline $\mathbf{1 1 .}$ & I 15 & 8.00 \\
\hline $\mathbf{1 2 .}$ & I 16 & 6.50 \\
\hline $\mathbf{1 3 .}$ & I 17 & 7.17 \\
\hline $\mathbf{1 4 .}$ & I 18 & 10.33 \\
\hline $\mathbf{1 5 .}$ & I 19 & 6.33 \\
\hline $\mathbf{1 6 .}$ & I 23 & 7.33 \\
\hline & CD (0.01) & 1.76 \\
\hline & & \\
\hline
\end{tabular}
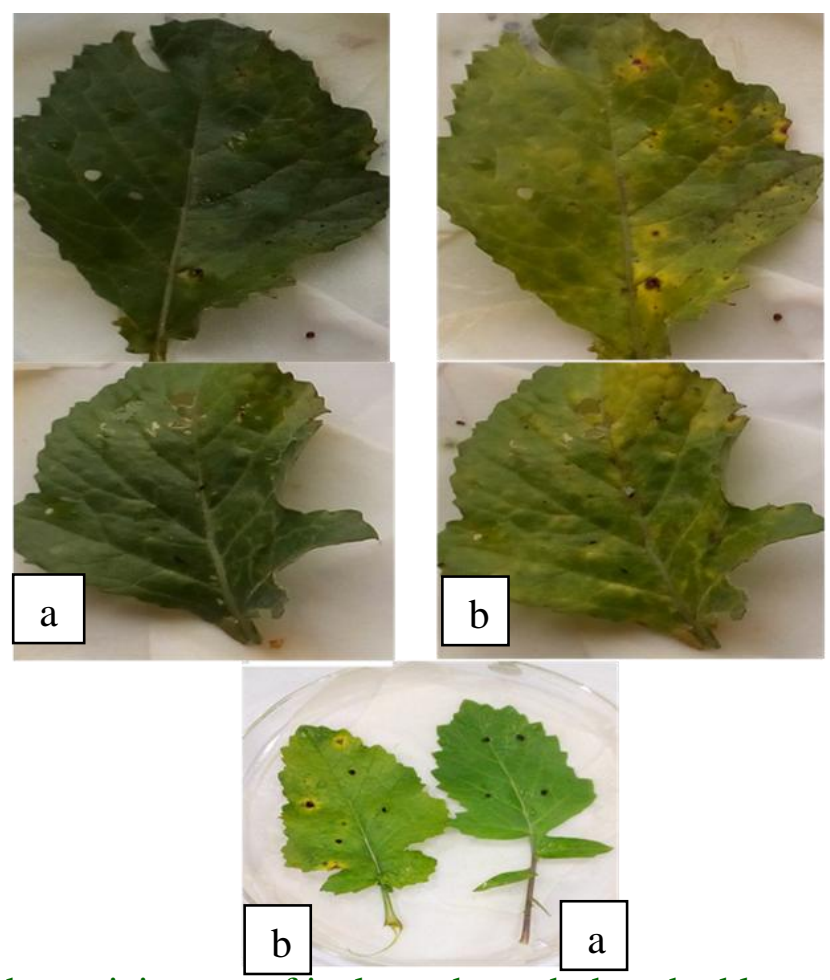

Fig.4 Pathogenicity test of isolates through detached leaves method

(a) Before inoculation \& (b) After inoculation 
Similarly, there were two groups of spore existed that showed significant difference in breadth of the spore; 10 isolates with spore width of $7.46-11.36 \mu \mathrm{m}$ and 6 isolates with spore width of 11.36-15.26 $\mu \mathrm{m}$. In the present study on $A$. brassicicola; isolates differ greatly in respect to morphological traits. Several workers have also reported, morphological variability among isolates of Alternaria spp (Goyal et al., 2011, Singh et al., 2007).

\section{References}

Agrios, G.N. (2008). Plant Pathology. Amsterdam: Elsevier Acad., Print

Deep, S., Sharma, P., Behera, N. and Chowdappa, P. (2014). Diversity in Indian Isolates of Alternaria brassicicola (Schwein) Wiltshire Causing Black Leaf Spot Disease in Cauliflower. Plant Path. J., 13: 232245.

Goyal, P., Chahar, M., Mathur, A.P., Kumar, A. and Chattopadhyay, C. (2011). Morphological and cultural variation in different oilseed Brassica isolates of Alternaria brassicae from different geographical regions of India. Indian $J$. Agril. Sciences, 81: 1052-1058.

Humpherson-Jones, F.M. (1989). Survival of Alternaria brassicae and Alternaria brassicicola on crop debris of oilseed rape and cabbage. Ann. Appl. Biol., 115: 45-50.

Hansen, J., Ruedy, R., Sato, M. and Lo, K. (2010): Global surface temperature change. Rev. Geophys., 48, RG4004, doi:10.1029/2010RG000345

Kumar, B. and Kolte, S.J. (2001). Progression of Alternaria blight of mustard in relation to components of resistance. Indian Phytopath., 54: 329-331.

Kumar, D., Maurya, N., Bharti, Y.K. and Kumar, K. (2014). Alternaria blight of oilseed brassica: A comprehensive review. African J. of Microbio Res., 8: 1816-1829.

Kolte, S.J. (1985). Diseases of Annual Edible Oilseed Crops, Vol. II, RapeseedMustard and Sesame Diseases. CRC Press Inc. Boca Raton, Florida, pp 135.

Meena, P.D., Chattopadhyay, C., Kumar, V.R., Meena, R.L. and Rana, U.S. (2005). Spore behavior in atmosphere and trends in variability of Alternaria brassicae population in India. J. Mycol. Plant Pathol., 35: 511-516.

Meena, P.D., Awasthi, R.P., Chattopadhyay, C., Kolte, S.J. and Kumar, A. (2010). Alternaria blight: a chronic disease in rapeseed mustard. J. Oilseed Brassica, 1: $1-11$.

Mondal, G. (2008). Evaluation of variety against Alternaria blight and Sclerotinia rot disease of rapeseed-mustard for old alluvial zone of the Northern part of West Bengal. Environ. and Ecol., 26: 2189-2191.

Ramegowda, G. and Naik, M.K. (2008). Morphological, cultural and physiological diversity in isolates of Alternaria spp. Infecting Bt-cotton. J. Mycol. Pl. Pathol., 38: 267-271.

Singh, D., Singh, R., Singh, H., Yadav, R.C. and Yadav, A. (2007). Cultural and morphological variability in Alternaria brassicae isolates of Indian mustard (Brassica juncea L. Czern \&Coss.). (in) Proceeding of the 12th International Rapeseed Congress, 26-30 March, Wuhan, China. 
How to cite this article:

Abhishek Kumar, Chanda Kushwaha, Chandan Kishore, Subhashish Sarkhel and Ravi Shankar Singh. 2020. Variability in the Population of Alternaria Brassicicola Causing Dark Spot of Mustard. Int.J.Curr.Microbiol.App.Sci. 9(02): 1425-1433.

doi: https://doi.org/10.20546/ijcmas.2020.902.165 